\title{
Exploration and Practice on Teaching of Air Pollution Control Technology in Higher Vocational Colleges
}

\author{
Jianhong Ji \\ Department of Chemical and Textile Engineering \\ Jiangyin Polytechnic College \\ Jiangyin, China 214400
}

\begin{abstract}
There are many drawbacks in the teaching of University courses. Teaching is the means of education. The purpose of teaching is not only to master professional knowledge, but also to promote the improvement of students' comprehensive quality. The characteristics of the course Air Pollution Control Technology, the characteristics of the students in Higher Vocational Colleges and the problems existing in the current teaching have been analyzed. By introducing the advantages of the project introduction and task-driven teaching method, combining with specific examples, it analyzes in detail the design project, the design scenario, the design task, and through the implementation of the reform of teaching methods. It not only improves students' interest and initiative in learning, but also lays a good foundation for cultivating students' comprehensive quality in Higher Vocational colleges.
\end{abstract}

Keywords-higher vocational colleges; Air Pollution Control Technology; course teaching; project introduction and taskdriven teaching method

\section{INTRODUCTION}

"Air Pollution Control Technology" course is a core course of environmental engineering technology, environmental monitoring and control technology specialties and so on in higher vocational colleges. It will lay a foundation for graduates to engage in environmental monitoring, environmental pollution treatment, environmental management and other related work. The curriculum is partial to theory, strong in theory and needs more calculation. This requirement is on the high side to Higher vocational college students, the teaching objectives of higher vocational colleges are generally oriented to the front line and the grass-roots level, cultivating good professional ethics, possessing the necessary cultural basic knowledge of the specialty, and mastering the basic theory needed by the specialty, professional knowledge and skills, able to engage in this professional or related work of high-quality technical skills skilled personnel.

There are a lot of problems in the course of teaching in Higher Vocational colleges. The main problem is that in order to finish almost all the knowledge points in the books, the teachers do not fully consider the students' acceptance ability, fill the classroom with water and duck-feeding teaching, and do not fully consider the cultivation of students' professional quality. In the traditional teaching process, the teaching method of "Air Pollution Control Technology" course in higher vocational colleges is mainly injection teaching, which makes the students' subjective initiative not fully play, resulting in the students' lack of innovation and practicality in analyzing and solving practical problems[1]. The following problems are common in Higher Vocational colleges: firstly, the students' cultural foundation in higher vocational colleges is relatively poor, while the contents of university science courses are generally theoretical, computational and complex, abstract concepts and difficult to accept; secondly, many students in higher vocational colleges have poor learning motivation, and some teachers' teaching methods and teaching methods. The means are single, the teacher doesn't care whether the teaching effect is good or not, the students are not interested in it. Third, students in higher vocational colleges like to play with their mobile phones, and they prefer practical teaching to just listening in class, but there are few practical teaching contents in theoretical courses such as Air Pollution Control Technology. Therefore, teachers in higher vocational colleges should change teaching methods to attract students, cultivate professional knowledge and skills, while cultivating students' sense of responsibility, dedication, teamwork spirit, organizational and coordination ability, pioneering and innovative ability and other non-professional qualities.

\section{ADOPTING PROJECT INTRODUCTION AND TASK DRIVEN TEACHING METHOD}

Project introduction and task-driven teaching method is to guide students to learn the thinking and methods of problem-solving, to train their skills, to deepen the mastery and application of curriculum knowledge, and to organize students to accomplish their tasks by means of understanding, thinking, analyzing and communicating knowledge under the guidance of teachers. Tasks should be applied to social production practice to cultivate students' innovative thinking ability, stimulate students' interest and motivation in learning by creating an atmosphere, integrate experimental and skill teaching methods, reduce the difficulty of curriculum learning, improve students' learning quality to the greatest extent, and cultivate students' sense of independence and teamwork, autonomy and self-reliance. From the thinking, through the task of breakthrough and project integration, abandon the knowledge level of pure teaching, combined 
with practical situation, innovative knowledge system, and then achieve the teaching purpose and learning objectives of the auxiliary and promotion [2]. The former teacher-centered teaching has been transformed into student-centered classroom teaching, which means that the whole teaching process is centered on students' autonomous learning and inquiry. Teachers not only play the roles of a student's learning instructor, supervisor and collaborator, but also play the role of modifying or supplementing or deepening the contents of student reports. Students should discuss the tasks assigned in advance by their teachers in groups, ask questions by themselves, and solve problems together through thinking and teachers' suggestions. Each group member needs to send a lecture, divided into the main lecture and the assistant lecture, must answer the teacher's two questions, comprehensive group results, PPT effect, reporting effect, answer questions and other links scored, this score as each member of the group stage assessment score.

\section{CAREFUlly Designing the TeAching Content}

There are many problems in the traditional teaching contents, such as too much exposition of air pollution control theory, inadequate explanation of engineering design and actual operation, which lead to the disconnection between theoretical knowledge and engineering practice, the lack of engineering design and hands-on ability, and the inability to enter the role immediately. This is also common in higher education at present. In addition, atmospheric pollution control is a continuously developing and rapidly renewing technology. After nearly a decade of development, various advanced and practical atmospheric pollution control technologies have emerged at home and abroad. Especially, many new technologies, such as desulfurization and dust removal integration technology, desulfurization and denitrification integration technology, have made great progress. With the leap forward, students are not only confronted with the traditional classroom teaching, but also with the new achievements and new technologies, which reflect the recent research and development at home and abroad. This is also an important reason for the lack of students' technical application ability [3].

At present, many project-based courses and textbooks only rename the chapter as a project, excerpts into tasks, and do not really understand the essence of project introduction task-driven teaching method. The course contents must be re organized according to the designed situational tasks. This puts forward higher requirements for teachers, in addition to the need to break the rules and regulations of conventional classroom teaching, as far as possible to design a good scene, arrangements for on-site teaching, integration of theory and practice teaching, teaching materials are only reference materials, teachers and students are required to add content according to the situational tasks, to the principle that theory is sufficient, the theoretical content is only a carrier, through this carrier to train students' professional ability and professionalism.

According to the requirements of scenario design, we can break the basic structure and framework of the original textbook. We design the course of Air Pollution Control
Technology into six projects. Each project designs several tasks and designs the real situation. For example, the introduction can be designed as project 1: completing the cause analysis report of fog and haze. Project scenario design: Jiangyin and its surrounding fog and haze occurred for 2 months in succession, air pollution, breathing difficulties, people panic. Require to refer to the contents of several chapters of the book, and consult a large number of information on the Internet, three people as a group, analyze the causes of Jiangyin haze and propose solutions and report, first report to complete the report, the need to master what common sense of air pollution, terminology, and then through discussion, analyze why the haze occurred in winter, Why the haze occurred in Jiangyin and other developed areas, why in recent years can be changed and so on; For example, item 2: accounting for boiler pollutant emissions. Project scenario design: The printing and dyeing enterprises opposite the college need a new $4 \mathrm{t} / \mathrm{h}$ steam boiler, through the selection, decomposed into a number of tasks: task 1: accounting for the coal consumption of this project; task 2: accounting for the theoretical air volume of this project; task 3: accounting for the actual air volume of this project, task 4, accounting for the theoretical flue gas generated by this project; task 5: calculate the actual amount of flue gas generated by the project; task 6: calculate the actual amount of smoke and dust generated by the project; task 7: calculate the $\mathrm{SO} 2$ concentration produced by the project; task 8 : Calculate the maximum concentration of $\mathrm{SO} 2$ in our department 1000 meters away from the chimney; task 9: calculate which department the maximum concentration of SO2 is; task 10: Through step-by-step analysis, the SO2 emission concentration is up to the standard, how to achieve the standard, the project is divided into a number of specific practical tasks, the book on the complex theory with this main line. The interlocking tasks go from the elementary to the profound and combine theory with practice, and makes full use of information technology, each group of independent consultation to solve.

\section{REFORMING THE EVALUATION SYSTEM AND METHOD}

Due to the poor foundation of students in Higher Vocational colleges, according to the conventional teaching, usually $30 \%$ of the results, $70 \%$ of the final results, often many students fail comprehensive results, and make-up examination fails, resulting in failure to graduate. Generally speaking, college students do not work hard at ordinary times. They want to pass the final exam as long as they give a temporary surprise before the final exam. Therefore, we cannot carry out quality education at ordinary times. After adopting project introduction and task driven teaching method, the proportion of the students' normal grades has increased greatly. The curriculum comprehensive score = theoretical score $* 80 \%+$ practical score $* 20 \%$. Among them, the theoretical score $=$ normal comprehensive score $* 30 \%+$ mid-term score $* 20 \%+$ final score $* 50 \%$. The ordinary comprehensive score $=$ task evaluation $* 50 \%+$ homework $* 30 \%+$ attendance $* 20 \%$. In peacetime, the periodic evaluation of each task includes: the report is incomplete, not smooth; a deduction of 10 points, the calculation process has 
a mistake deduction of 10 points, until 50 points deduction. PPT is not clear, not neat, with a deduction of 2 points until the 10 point deduction. The report was not smooth and unclear, with a deduction of 2 points until the 10 point deduction. The voice is not loud enough to deduct 5 points. Teachers on the report content in class questions, except the lecturer, assistant group members must answer questions, a total of 2 questions; each question 5 points, a wrong answer to a question deducted 5 points.

\section{CONCLUSION}

Years of practice has proved that only by adopting good teaching methods such as project-oriented task-driven, carefully designing the teaching work of Higher Vocational colleges, designing projects, designing scenarios, designing tasks, carefully organizing, boldly innovating and putting them into practice, can students' interest and initiative in learning be improved. Only by attracting students can we cultivate college students with professional and nonprofessional qualities.

\section{REFERENCES}

[1] Wang Chen. Exploration on the Teaching Reform of Air Pollution Control Technology Course [J]. ournal of Heilongjiang Vocational College of Ecological Engineering, 2013, 26 (1): 85.

[2] Zhang Pingping. Task-driven teaching reform of computer course project introduction [J].Computer Age, 2018,8:76 [3] Liu Guohua. Exploration and Practice of Teaching Reform of Air Pollution Control Technology Course [J]. Journal of Henan Mechanical and Electrical College, 2011, 19 (4): 109. 